IZA DP No. 4822

A New Model for Equitable and Efficient

Resource Allocation to Schools: The Israeli Case

Iris BenDavid-Hadar

Adrian Ziderman

March 2010 


\title{
A New Model for Equitable and Efficient Resource Allocation to Schools: The Israeli Case
}

\author{
Iris BenDavid-Hadar \\ Bar-Ilan University \\ Adrian Ziderman \\ Bar-Ilan University \\ and IZA \\ Discussion Paper No. 4822
March 2010 \\ IZA \\ P.O. Box 7240 \\ 53072 Bonn \\ Germany \\ Phone: +49-228-3894-0 \\ Fax: +49-228-3894-180 \\ E-mail: iza@iza.org
}

Any opinions expressed here are those of the author(s) and not those of IZA. Research published in this series may include views on policy, but the institute itself takes no institutional policy positions.

The Institute for the Study of Labor (IZA) in Bonn is a local and virtual international research center and a place of communication between science, politics and business. IZA is an independent nonprofit organization supported by Deutsche Post Foundation. The center is associated with the University of Bonn and offers a stimulating research environment through its international network, workshops and conferences, data service, project support, research visits and doctoral program. IZA engages in (i) original and internationally competitive research in all fields of labor economics, (ii) development of policy concepts, and (iii) dissemination of research results and concepts to the interested public.

IZA Discussion Papers often represent preliminary work and are circulated to encourage discussion. Citation of such a paper should account for its provisional character. A revised version may be available directly from the author. 
IZA Discussion Paper No. 4822

March 2010

\section{ABSTRACT \\ A New Model for Equitable and Efficient Resource Allocation to Schools: The Israeli Case}

This paper sets out a new budget allocation formula for schools, designed to achieve a more equitable distribution of educational achievement. In addition to needs-based elements, the suggested composite allocation formula includes an improvement component, whereby schools receive budgetary allocations based on a new incentive measure developed in this paper (Improvement in the Educational Achievement Distribution, or IEAD). The development of the budget allocation formula is demonstrated utilizing Israeli data. Large scale, nationwide data sets relating students' academic achievement to student background variables, teacher profiles and school characteristics, were analyzed to identify appropriate needs-based formula components and to estimate their weights. The results are compared with the funding formulas currently used in Israel.

JEL Classification: $\quad 122$

Keywords: school finance, formular funding, needs-based funding, schools resource allocation, Israel

Corresponding author:

Adrian Ziderman

Economics Department

Bar-Ilan University

52900 Ramat Gan

Israel

E-mail: zidera@mail.biu.ac.il 


\section{Introduction}

The method by which the state allocates the budget to the school system can serve as an important instrument for achieving desired improvements in levels of educational attainment, social equity and other social policy targets. In many school systems, the allocation of school budgets is done according to a needs-based funding formula. A needsbased formula allocates budgets differentially to schools on the basis of the socioeconomic background of the student body; schools with students whose parents have low levels of education, who have a large number of siblings, and those living in rural areas will be in receipt of larger budgetary allocations.

A needs-based school funding formula distributes education resources on a per-pupil basis according to the student's background. The allocation formula used in England (a statutory requirement of the School Finance Regulations) provides an example of a needs-based formula. This formula assigns high weights to student background factors such as whether or not a pupil is entitled to a free meal at school (Adnett et al., 2002). The formula used in Holland compensates for students of disadvantaged backgrounds; a larger compensation is allocated to non-Dutch students from a disadvantaged background than to Dutch students from a disadvantaged background (Ritzen et al., 1997; Canton \& Webbink, 2002). A third example is that of the state of Florida, which allocates larger compensatory funds dichotomously, according to student background variables such as English as a Second Language (ESL) and eligibility for hot meals (Owens \& Maiden, 1999). Similarly, the city of San Francisco’s resources are also distributed dichotomously, according to the specific needs of each student, such as special education, ESL, and socioeconomic status (Shambaugh, Chambers, \& DeLancey, 2008) ${ }^{1}$. Israeli allocation at the primary school level also compensates students according to their background, but unlike the dichotomous 
compensation allocation in use in San Francisco and Florida, the compensation is 'diagonally' allocated. That is to say, the extent of compensation is positively correlated with the depth of the need (Shoshani, 2001).

Needs-based formula funding is generally regarded as an improvement on traditional, evenly-based school funding (e.g., input-based methods). School funding formulas can be instruments of educational policy, including policies aimed at change and reform. Because formulas can operate at the school level, and because they can be sensitive to a wide variety of cost factors and inputs (e.g., different categories of students), they can be effective instruments for reform, provided that they are properly deployed (Cohn \& Geske 1990; Ross \& Levacic, 1999; Levacic \& Vignoles, 2002).

Evenly-based funding formulas offer horizontal equity, but do not provide differential levels of resources based on differing needs. Resource allocation to Israeli high schools is of this kind ${ }^{2}$. A funding formula designed to provide equality of inputs is regressive (i.e. it enlarges the achievement gap). This is so because evenly-based funding does not encourage vertical equity, considering that the needs of students vary according to their differing academic-achievement starting points; equality of inputs is actually regressive in that it allocates to schools the same resource amount, regardless of the average profile of academic starting points of the student body.

While needs-based funding provides additional resources to low-achieving schools with greater needs, there is also an expectation that these additional budgets will be used to raise academic achievements in these schools. The outcome of the debate on whether "money matters” - whether additional school resources lead to educational attainment improvement has been largely resolved positively. But if there are no incentives for improvement, many low-achieving schools, in receipt of additional, differential funding, may continue to tread water rather than improve. Under needs-based budgeting, the continuation of additional 
differential funding is not contingent upon progress in academic achievement. Thus, an allocation formula based solely upon needs-based features will lead to greater vertical equity, but might also preserve the current achievement distribution, given that incentives for progress are lacking. Alternatively, a school budget allocation formula based solely on incentives for progress (incorporating improvement components) might lead to a widening of the achievement gap, because such a formula ignores vertical equity.

The literature does not provide a definitive answer to the question of whether equity and efficiency in educational finance are mutually exclusive or compatible. Nevertheless this paper, rather than treating equity and efficiency as dichotomous concepts, attempts to combine them using a distributional approach. Woessmann (2006) claims that, efficient education systems can create economic growth, and that equitable systems can create social cohesion. This paper suggests that both efficiency and equity can be enhanced by distributional output-oriented reforms, in which the state generally sets a regulatory framework that ensures accountability and funding. When school funding formulas are designed this way, education systems can advance efficiency and equity in parallel.

The paper argues that both equity and efficiency may be achieved by developing a composite budget allocation formula incorporating both needs-based and improvement elements. With this outcome in mind, we develop (in Section 4) a new concept: the “Improvement in the Educational Achievement Distribution” (IEAD). The new formula addresses issues of both horizontal and vertical equity, as well as offering schools rewards for educational improvement.

The formula is developed using Israeli data; this setting is thought to be an appropriate one because Israel is a diverse society encompassing ethnic minorities and immigrant groups. Moreover, the budgetary allocation system currently in use is neither efficient nor equitable, and therefore in need of reform. 
Dissatisfaction with the allocation mechanism is evident in Israel (Central Bank of Israel, 2008; Kopp, 2008; Dovrat commission report, 2005). For instance, in response to litigation concerning the inequity of Israeli school finance, the Israeli Supreme Court recently instructed policy makers to transform the primary-school funding formula. Klinov (2008) reports on deficiencies at all three schooling levels in the funding formulas currently in use in Israel; however, empirical research on the issue of resource allocation to the Israeli school system is scarce.

In addition to including the IEAD improvement-based component, the new formula developed in this paper includes a needs-based component that improves on those used in the differential formula currently employed for primary schools, based on the recommendations of the Shoshani Committee (2001). Furthermore, in accordance with the recommendations of the Dovrat Commission (2005), which have hitherto not been adopted, the proposed formula is to be applied uniformly to all schooling levels. Based on an analysis of extensive national data sets, then unavailable to these two committees, the proposed formula encompasses changes both in the components of the needs-based element and in their relative weights.

The plan of this paper is as follows. In the next section, some major features of the Israeli education system are described. The methodological Section 3 lays out the conceptual model, data sources and definitions of the variables used and regression analysis results. In Section 4, our new measure of educational progress - IEAD - is outlined; this constitutes the progress element in the new formula. Section 5 shows how the new allocation formula is designed and estimated on the basis of the regression analysis; the new composite formula is compared with those currently in use. Recent policy initiatives, not always positive, are discussed in the final Section 6.

\section{Current practice}




\subsection{The school system}

\section{Population diversity}

Throughout its sixty years of statehood, a key feature of Israel’s educational policy has been the achievement of high levels of, and equality in, educational attainment for its diverse population. Israel is a small country (about seven million residents), but its population is diverse. Seventy-six percent of its permanent residents are Jews, some of them immigrants from Western and Central Europe, North Africa and other Middle East countries, or their descendents. In the recent period 1990-2008, 1,035,200 new immigrants (fifteen percent of the population) came to Israel, 76,100 from Ethiopia and 799,590 from the former USSR. The rest of the population comprises ethnical minorities, mostly Arab residents $(1,413,300)^{3}$.

Diversity is also found in the differing levels of economic material well-being. Income inequality in Israel is high and increasing. The Gini coefficient of income inequality (0.3878) has increased and now even exceeds that of the US. In recent years, the average income of the highest decile has been increasing, while the average income of the lowest decile has declined. The average standard of living has increased, yet 24 percent of permanent residents are poor, as are 34 percent of Israeli children ${ }^{4}$.

\section{School structure ${ }^{5}$}

The Israeli school system is primarily public and comprises primary, lower secondary (middle) and upper secondary (high) schools. Pluralism is a central feature of the system; alongside the system of state general education, there are separate systems of state-religious schools, education in Arabic for minority students and separate, independent ultra-orthodox religious schools. Approximately 77 percent of the total student population is enrolled in Hebrew education, and 23 percent in Arab education. Most of the official education system ${ }^{6}$ was restructured to be comprised of three levels: six years of primary education (grades 1 through 6), three years of lower secondary schooling (grades 7 through 9), and three years of 
upper secondary schooling (grades 10 through 12); the remaining official schools, which have not undergone the restructuring, comprise two levels only - primary schools (grades 1 through 8) and secondary schools (grades 9 through 12).

Israel's official Hebrew education encompasses two divisions: state and statereligious ${ }^{7}$. Both these divisions belong to the state, but differ with regard to religious beliefs and practice. These differences were manifested by the establishment of separate schools, school curricula, and school personnel. The schools of the Ultra-Orthodox are separate from the main stream of state education, yet enjoy monetary support from the state.

There are three post-primary level educational streams - regular-academic, technological-vocational and agricultural training. The comprehensive high school now is the most common type of schooling, accounting for some 70 percent of post-primary enrollments and including both academic and technological streams.

\section{Achievement distribution}

The Israeli student achievement distribution is characterized by a low level of achievement combined with a widening achievement gap, as evidenced in various international comparative examination studies. This is despite the declared policy goal of narrowing the achievement gap upwards. In Progress in International Reading Literacy Study (PIRLS, 2001), an international comparative study on literacy on the forth grade, Israeli students' level of achievement was ranked 23rd, out of 45 participating countries. The average score of Israeli students was 509 (compared with an overall average of 500). However, it should be noted that Arab and ultra-orthodox students were excluded from the sample; their inclusion would very likely have further lowered the Israeli average. In the Program for International Student Assessment (PISA, 2000), an international comparative study on literacy among 15 years old students, Israeli students were ranked in the 30th place, out of 41 countries. 
In international comparative examinations on Mathematics and Science, Trends in International Mathematics and Science Study (TIMSS, 1999), the Israeli students' level of achievement is lower than average. The Israeli students' level of achievement in Mathematics was ranked 28th, out of 38 countries participating in the test. Only five percent of Israeli students were “excellent” in Mathematics and only seven percent in Science. Again, only Jewish students were examined; if other minorities had been included, it is likely that the Israeli achievement level would have been lower.

According to the Israeli Central Bureau of Statistics (2006), not all youth in the relevant age group are students - only some 80 percent of them attend school. Furthermore, only less than 50 percent of this age group (including both students and non-students) performed well enough on the matriculation exams to entitle them to a matriculation diploma; of these, only forty percent gained a diploma that is sufficient for acceptance to Israeli universities.

The distribution of educational achievement in Israel is also characterized by wide gaps. Tsur and Zussman (2008) examined the differences between the matriculation examinations achievement of Israeli students from various socioeconomic backgrounds and found widening gaps in indicators of excellence between the achievement of students from weak socioeconomic backgrounds and those from strong backgrounds. Compared to OECD (Organization for Economic Co-operation and Development) countries, Israeli students exhibit the widest achievement gap. Amongst industrialized countries, the scholastic achievements level of Israeli students is among the lowest and the educational gaps among Israeli students are the widest. Furthermore, the achievements of the higher decile of Israeli students are below those of similar students in all of the industrialized countries (Ben-David, 2003; Dovrat, 2005; Dahan \& Ben-Basat; 2004, Dahan, al el, 2002; Mevarech \& Liberman, 2004). The achievement gap is related to ethnicity, socio-economic level, country of origin, 
new immigrant status, and residence area, i.e. periphery versus the centre (Dahan et al., 2002; BenDavid-Hadar, 2008).

Given this discouraging Israeli student achievement distribution, it is thought that a reshaped school resource allocation system may serve a key corrective role in narrowing the achievement gap and boosting the level of achievement, in line with policy makers’ goals.

\subsection{Current funding formula}

This section explains why it is necessary to develop a new needs-based element in the school funding formula. Differing budget allocation formulas are applied at the various schooling levels within the state system: an evenly-based allocation formula for high schools, separate needs-based formulas (with five elements) for Hebrew and for Arab education at the middle school level, and a needs-based formula (with seven elements) at the primary school level (see Table 1). The overall primary and middle school budget allocation comprises two components; the major component, the fixed budget, accounts for some 87 percent of the total budget allocation, while the remaining 13 percent constitute the compensating, needs-based budget component.

The primary school budget allocation is the product of the number of students and the average differential (student) index for the school (Shoshani Committee, 2001); resources are allocated to schools in terms of instructional hours rather than in monetary terms. The differential index is a per-student index calculated according to a needs-based formula (i.e., a larger budget is allocated to needy students according to the depth of their needs), with an added "national priority” element (i.e., larger budget is allocated to students living in areas that were defined as 'national priority' areas, such as those near Israel’s borders). A common differential index is used for both Hebrew and Arab education. The elements and relative weights, as set out in Table 1, Column 1, are as follows: mother's level of education (15\%), father's level of education (15\%), number of siblings (10\%), new immigrant status (20\%), 
immigrant from developing countries status (10\%), national priority status (20\%), and periphery location status, i.e., schools located in a distance from the nearest of the three largest cities in Israel (10\%). Most of the weights were derived from regression analyses examining the correlates between students' background characteristics and students' achievement. 
Table 1: Current and proposed needs-based formula elements and weights

\begin{tabular}{|c|c|c|c|c|c|}
\hline \multirow{3}{*}{ Formula elements } & \multicolumn{4}{|c|}{ Current formula weights } & \multirow{3}{*}{$\begin{array}{c}\begin{array}{c}\text { Proposed } \\
\text { formula } \\
\text { weights }\end{array} \\
\begin{array}{c}(3) \\
\text { Unified: }\end{array} \\
\text { all school } \\
\text { levels } \\
\text { (Student- } \\
\text { based) }\end{array}$} \\
\hline & \multirow{2}{*}{$\begin{array}{c}\text { (1) } \\
\text { Primary } \\
\text { schools } \\
\text { (Student- } \\
\text { based) }\end{array}$} & \multicolumn{2}{|c|}{$\begin{array}{c}\text { (2) } \\
\text { Middle schools } \\
\text { (School-based) }\end{array}$} & \multirow[t]{2}{*}{$\begin{array}{c}\text { High } \\
\text { schools }\end{array}$} & \\
\hline & & Minorities & Jewish & & \\
\hline Mother's education level & 15 & -- & -- & -- & 23 \\
\hline Father's education level & 15 & 25 & 25 & -- & 13 \\
\hline Number of siblings & 10 & 12.5 & 15 & -- & 6 \\
\hline New immigrant status & 20 & -- & 15 & -- & 8 \\
\hline $\begin{array}{l}\text { New immigrants from } \\
\text { developing countries status }\end{array}$ & 10 & -- & -- & -- & 8 \\
\hline $\begin{array}{c}\text { Residence: Periphery } \\
\text { SES }\end{array}$ & $\begin{array}{l}10 \\
--\end{array}$ & $\begin{array}{l}25 \\
--\end{array}$ & $\begin{array}{l}20 \\
--\end{array}$ & $\begin{array}{l}-- \\
--\end{array}$ & $\overline{-}-\overline{1}$ \\
\hline School in mixed cities & -- & 12.5 & -- & -- & -- \\
\hline National priority status & 20 & -- & -- & -- & -- \\
\hline Ethnicity & -- & -- & -- & -- & 19 \\
\hline Income & -- & 25 & 25 & -- & -- \\
\hline
\end{tabular}

At the middle school level, a two-stage allocation mechanism is in place (Nesher, 1996). First, the total middle school budget is divided between the two ethnic groups, according to the total number of students in each group. As noted above, some thirteen percent of the basic standard budget is set aside for compensatory budget allocation; the remainder comprises the fixed budget allocation. The percentage of schools entitled to receive a differential budget is determined by the Ministry of Education (in 2006, 75\% of Jewish schools and all non-Jewish schools were entitled to receive differential budgets). The compensating budget is differentially allocated to each eligible school at the second stage, after a deduction of ten percent accruing to the municipal authorities. Each eligible school within its respective ethnic group receives a relative, differential budget; separate differential 
formulas are employed for each ethnic group. This two-step allocation mechanism has the undesirable effect of allocating lower budgets to the neediest (minority) student groups.

The elements of the differential index for Jewish and Minority middle schools are set out in Table 1, Column 2. The elements of the formula for Jewish students are: percent of low-income families (25\%); percent of fathers with low-level education (25\%); percent of large families (15\%); percent of new immigrants (15\%); and a periphery index based on the distance from the nearest of the three largest cities (20\%). The elements of the differential index for Arab students are: percent of low income families (25\%); percent of fathers with low-level education (25\%); percent of large families (12.5\%); periphery element (25\%), in this case referring to families from unrecognized localities (12.5\%) and schools in small residences (12.5\%); and schools in mixed $\operatorname{cities}^{8}$ (12.5\%), (Nesher, 1996).

Overall, the current system of school budgeting in Israel is in need of revision. High schools are budgeted on an even-basis system, which provides horizontal but not vertical equity, and there are no incentives for improvement in performance. Needs-based budgeting is in place for primary and middle schools, but the formulas employed are deficient, both in terms of the elements used in the formula and the weights assigned to them; this will be demonstrated in Section 5). For these schools as well, progress incentives are lacking. The cost, in terms of the overall quality of the educational system, is not small. Comparative international evidence attests to a relative decline in Israeli schools' educational attainment and Israeli students display relatively low achievements in international examinations, as described in section 2.1. Together with the widening of the achievement gap (Ben-David, 2000), this portends ill for Israel's long-term economic and social progress. The new composite funding formula developed in this paper may go some way towards a reversal of these trends. 


\section{Methodology}

This section describes the methodology used in the design of an improved allocation formula, improved both in terms of better addressing school needs and of promoting progress in student academic achievement. The conceptual model underlying the statistical analysis is presented; this is followed by an account of the data sources and the variables used in the statistical analysis.

\subsection{Conceptual model}

The conceptual model, shown in Figure 1, presents two kinds of relationships between the variables. The first is the direct relationships between student performance and various background features. This is shown by the solid-line arrows in Figure 1. This provides a direct measure of the contribution of each explanatory variable to variation in academic achievements. The beta coefficients for the student background variables are used to identify the needs-based components and size of weights to be included in the new funding formula, as will be explained in Section 5; they will also indicate which of the components used in the current formula need to be excluded, replaced or assigned different weights. Teacher profiles and school characteristics are employed as control variables because they are most likely to affect performance, but are not relevant elements in the need-based funding formula. 


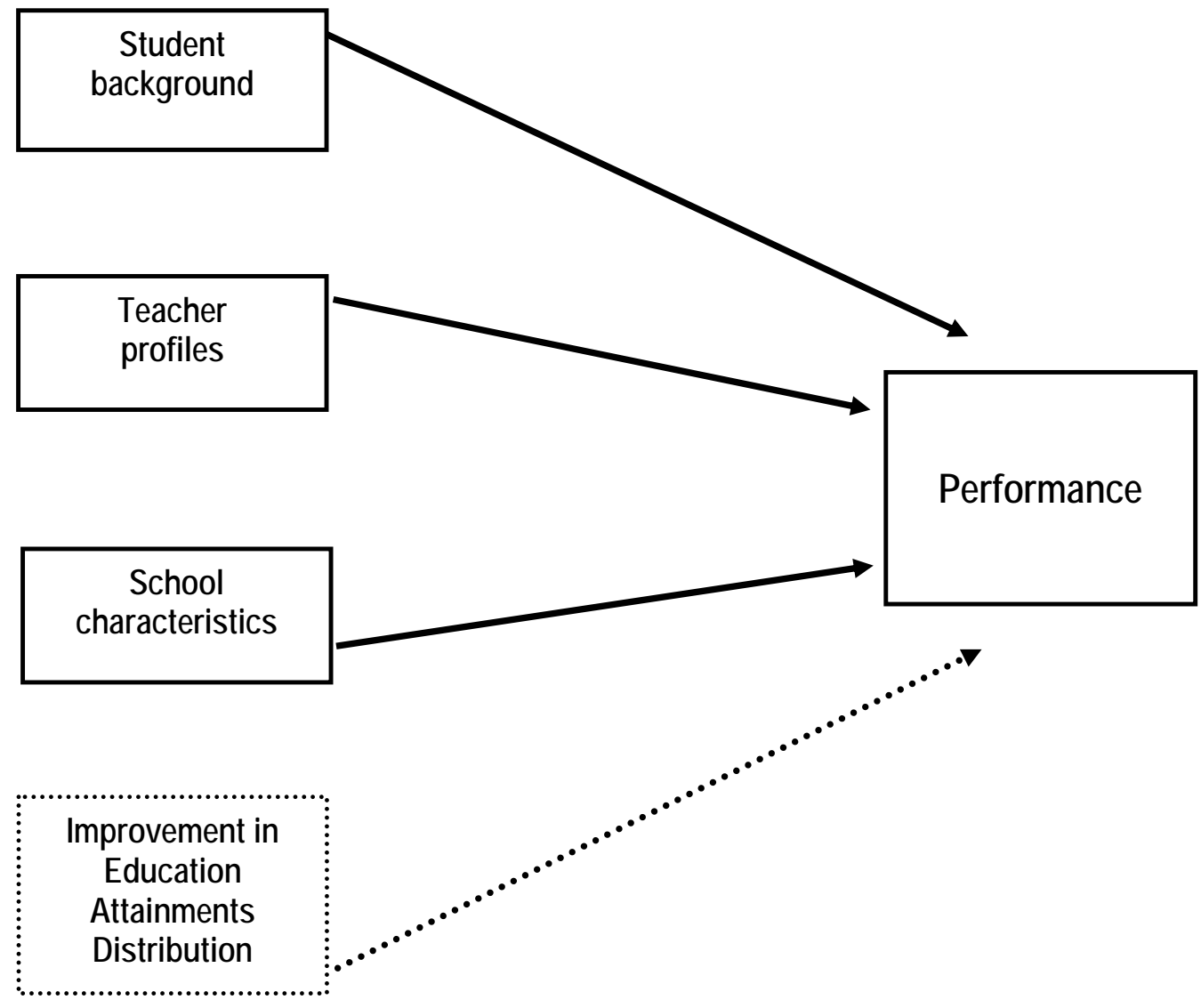

Figure 1: The conceptual model

OLS regression analysis is employed, a method widely used in the literature to measure the relationships between student performance and student background characteristics (Jenkins, Levacic, \& Vignoles ,2006; Gould, Lavy, \& Paserman, 2004; Carnoy, Gove, \& Marshall, 2007). The dotted arrow represents a second kind of relationship, indicating a reward for academic improvement (to be explained in Section 4).

\subsection{Data}


Extensive data sets were obtained by special request from the records of the Israeli Ministry of Education, comprising three levels of schooling (i.e. primary, middle, and high school). However, only high school data were available on the student (individual) level. The data for the other two levels of schooling (primary and middle schools) were available only at the school level. Therefore, the regression results for these levels are not reported here, although they were taken into account in formulating the policy suggestions included in this paper; these results are available on request.

\section{High school data}

The data set contains nation-wide matriculation examination scores ${ }^{9}$, at the student level, for the year 2001. The matriculation examinations in Israel are centralized. The entire process is governed by the Ministry of Education. The exams on all compulsory subjects (see below) and most optional subjects are designed and written by the Ministry, thereby creating a standard measure of the students' knowledge throughout the country. All students who are Israeli citizens take one or more of the nation-wide matriculation examinations.

The data relate to about 84,000 students ( $25 \%$ are minority students), in some 1,100 high schools. Included in the data base are all the students' scores at the final examinations for each subject in which students were tested, and the level of the subject material at which they were examined. The second part of the data set contains information on student background features such as the level of the mother's and the father's education, ethnicity, origin of birth, number of siblings and residence. The data also include teacher profiles (seniority and education level) and school characteristics such as school size and type of supervision (state or state-religious).

\subsection{Variables}

Two types of variables were defined: dependent (endogenous) variables, and independent (exogenous) variables. 


\section{Dependent (endogenous) variables}

The dependent variables relate to student performance. Two main types of high school performance data are used, one relating to performance level and the other to performance quality. The level of performance is represented by the Mathematics matriculation score, which was calculated with respect to the differing levels of Mathematics (i.e. number of study units, or "credit points") in which individual students were examined. This is thought to be an improvement on the traditional measure of performance in terms of the overall matriculation (Bagrut) mean score. It was chosen as more representative of the level of high school achievement, because it is an obligatory subject in the matriculation examinations and the examinations are standard for all students; this facilitates student comparisons.

A quality measure was introduced because of wide variations amongst students in the scope of their matriculation diploma. Individual diplomas vary because of a differing number of subjects taken and differing study levels within some subjects. Thus a diploma may relate to the minimum required credit points (twenty one) or to a more comprehensive study plan of up to fifty credit points. Quality of performance is defined as the summation of the products of every subject score by the number of points in each subject. This is thought to more reliable than the overall average matriculation score, because it reflects the variation in performance. For example, a student would be considered an excellent student if he or she scores 100 on the variable "overall matriculation mean score”. However, this score of 100 may correspond to a wide range of scores on the variable "quality", from the lowest value of 2100 (100* 21 credit points, the required minimum) to the highest value of 5000 (100* 50 credit points), representing a different interpretation of “excellence”.

\section{Independent (exogenous) variables}

Four sets of independent variables were defined. Three vectors of need-based variables were used in the regression analysis: student background (to estimate the formula 
weights) and teacher profiles and school characteristics (as controls). A fourth measure of academic progress, the IEAD improvement variable, was defined but not employed in the regression analysis, as explained subsequently.

The student background category consists of three types of variables. First, some student variables were defined directly, relating to gender, origin of birth, immigration year, and ethnicity ${ }^{10}$. Second, the student socio-economic status variable (SES) was defined indirectly, in the absence of Ministry of Education information on student SES. The SES measure used is based on student residence location, using an SES index developed by the Israeli Central Bureau of Statistics (CBS, 2006). This index assigns to each local authority a number ranging from one to ten, where a lower number indicates lower average SES. Third, parental characteristics were defined, relating to fathers' and mothers' education level and to fathers' and mothers’ origin of birth.

The teacher profile variables (used as controls) comprise information on teacher's education (which is defined as a continuous variable, with the doctorate receiving the highest ranking) and seniority, defined by number of years in the teaching profession.

School characteristic control variables were included: school size, average school SES level, supervision (state, state-religious), and school type (the new school structure consists of three schooling levels while the old structure comprises only primary and secondary schools). 
Table 2: Variables Listing

\begin{tabular}{|c|c|}
\hline Dependent variables & Independent variables \\
\hline $\begin{array}{l}\text { Primary schools: Fifth grade } \\
\text { achievement in final examinations } \\
\text { (Meitsav) } \\
\text { Middle schools: Eighth grade } \\
\text { achievement in final examinations } \\
\text { (Meitsav) } \\
\text { High schools: performance level } \\
\text { and quality in the matriculation } \\
\text { examination (Bagrut) }\end{array}$ & 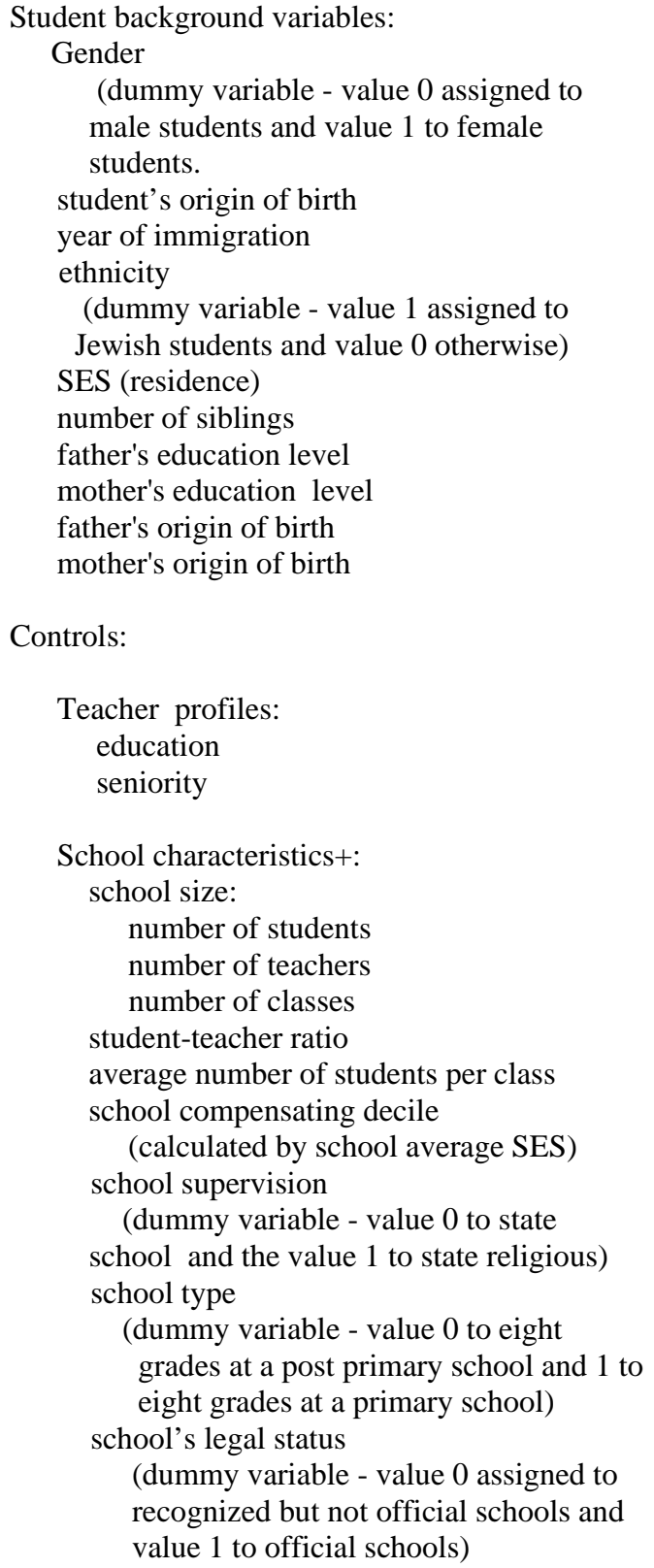 \\
\hline
\end{tabular}

+ Other control variables were also used 
Table 2 lists the variables used in the regression analysis; the relationships amongst these variables are indicated in Figure 1. The analysis of high schools is at the student level.

Since suitable data for measuring the improvement component (IEAD) is yet unavailable in Israel (though such information is currently in preparation), this component was not included as a variable in the regression analyses reported below. In the absence of a direct estimate of the size of this variable, a proxy measure for this formula component was used, based on the results of external, value-added research. When suitable Israeli data for the direct measurement of IEAD becomes available in the near future, the size of this formula element will be estimated directly from an extended regression model, based on a measure of school value-added in Israel. The IEAD concept is explained in detail in the following Section 4; meanwhile, we present the results of the regression analysis.

\subsection{Regression Results}

The results of regression analyses measuring the direct relationship between student performance and student background variables are now presented. An explanation of how the regression beta coefficients for the student background variables are translated into new formula elements and weights is given in Section 5.

In addition to regressions for the total sample, separate regressions by ethnicity were executed (Jewish versus Arab student performance), while others entailed separate analyses for each ethnic sub-group (Arabs, Druze, Bedouin). Separate regressions were also run including various interaction effects. Additional regressions were executed for other schooling levels. While we report only the findings of the total sample regressions on the high school level, including parental education interaction effects, some key results from other regression runs are referred to in the following discussion, as necessary. Full results from these other regression runs are available from the authors, on request. 
Results for the student background variables are reported in Table 3; results for the controls are not reported. Amongst the student background variables, parental education and ethnicity make the greatest contribution to explaining the variations in student achievement.

Table 3: Regression analysis: Effect of student background variables on high school student performance

\begin{tabular}{|c|l|l|}
\hline \multirow{2}{*}{ Explanatory variables+ } & \multicolumn{2}{|c|}{ Performance } \\
\cline { 2 - 3 } & \multicolumn{1}{|c|}{ Level } & \multicolumn{1}{c|}{ Quality } \\
\hline Gender & Ns & $-0.07^{* *}$ \\
\hline $\begin{array}{c}\text { Number of years in Israel (for new } \\
\text { immigrants) }\end{array}$ & $0.07^{* *}$ & $0.03^{* *}$ \\
\hline Ethnicity & $0.04^{* *}$ & $0.07^{* *}$ \\
\hline Residence (SES) & $0.04^{* *}$ & Ns \\
\hline Number of siblings & $-0.04^{* *}$ & $-0.04^{* *}$ \\
\hline Parents' education interaction & $0.23^{* *}$ & $0.24^{* *}$ \\
\hline Mother's education level & $0.06^{* *}$ & $0.05^{* *}$ \\
\hline Father's origin of birth & $0.04^{* *}$ Israel & Ns \\
\hline $\mathrm{R}^{2}$ & 0.14 & 0.13 \\
\hline
\end{tabular}

${ }^{*} \mathrm{p}<0.05,{ }^{* *} \mathrm{p}<0.01$

Ns Variable is not significant

+ Non-significant variables in these regressions are not reported in the table. These variables include the father's level of education and the student's origin of birth.

The effect of the parental education interaction variable is large (quality measure of performance $\beta=0.24^{* *}$ and achievement level of performance $\left.\beta=0.23^{* *}\right)$. The mother's education ( $\beta=0.05^{* *}$ and $\left.\beta=0.06^{* *}\right)$ appears to be more important than the father's education, which was not found to be significant in the model including the interaction effect (and is therefore not reported). However, the father's education coefficient is significant in the same model with no interaction effect $\left(\beta=0.1^{* *}\right)$, though this effect is still smaller than that of the mother's education $\left(\beta=0.2^{* *}\right)$; the opposite result was found for minorities ${ }^{11}$. 
Ethnicity also contributes to explaining achievement variation, though the reported beta coefficients for ethnicity on the high school level are rather weak $\left(\beta=0.04^{* *}\right.$ and $0.07^{* *}$, respectively for the level and quality measures of performance).

The contribution of the remaining student background variables to explaining achievement variation is low. The number of siblings variable is negatively related to achievements $\left(\beta=-0.04^{* *}\right)$. Residence SES also explains variation in student achievement $\left(\beta=0.04^{* *}\right)$. New immigrant achievements are related positively to the length of time spent in Israel $\left(\beta=0.03^{* *}\right.$ and $\left.\beta=0.07^{* *}\right)$.

\section{Rewarding educational progress and the IEAD concept}

\subsection{The need to incorporate an improvement component}

The central argument of this paper is that school budget allocation formulas should include an incentive element that encourages schools to improve the educational attainment of their students. We argue that, to this end, the formula should be a composite of two major components: a needs-based component and an improvement component. The needs-based component is a differential budget that allocates resources according to students' differing academic-achievement starting points in a way that sustains vertical equity. A formula based solely on the principle of budgeting according to student starting points (determined by student background characteristics) is inefficient, since it fails to encourage schools to move towards improved student attainment. Thus schools with low-achieving students receive larger budgets regardless of the progress made.

The improvement component is an incentive mechanism designed to achieve the improvement of the educational achievement distribution. How should progress in student educational attainment be defined, in terms of an improvement component in the budget 
allocation formula? For this purpose, we introduce a new concept - Improvement in Educational Achievement Distribution (IEAD).

The design of the incentive component proposed in this paper is innovative, as it comprises movement towards enhanced academic achievement, while controlling for the size of the educational achievement gap. Thus IEAD has two elements, relating to raising the level of educational attainment and narrowing the educational achievement gap. Both elements are important. An incentive component that is designed only to increase the level of performance (i.e. by allocating larger budgets to schools that raised the level of educational performance) might encourage a widening of the achievement gap, leading to enlargement of the income gap and to wider segregation of society. An incentive component designed solely to narrow the achievement gap, may narrow it downwards by lowering the level of achievement in order to narrow the achievement gap. This would mean that programs of excellence would not receive appropriate funding. Thus, the proposed IEAD incentive mechanism is designed to meet the dual objectives of encouraging increased levels of academic performance and of narrowing the educational achievement gap. As explained, the improvement features would lead toward achieving the combined goals of higher achievement and narrow achievement gaps. An additional budget is allocated to those schools that have succeeded in registering an improvement in the educational achievement distribution.

Hanushek (1996) argues that, in order to improve U.S. Schools, it is essential for improved performance incentives to be introduced in schools. Hanushek elaborates that incentives based upon student outcomes hold the largest hope for improving schools. He concludes that improvement is much more likely if policies are built on what students actually accomplish and if good performance by students gets rewarded. Springer and Winters (2009) review recent performance-related compensation reforms in U.S. states and districts such as 
Denver, New York City, Dallas, and Houston. These pay-for-performance programs are still being implemented or evaluated.

Furthermore, recent studies report on the positive impact of pay-for-performance programs. Muralidharan and Sundararaman (2008) and Lavy (2002) found that student and teacher incentive programs in India and Israel improved student outcomes. Moreover, empirical studies argue for the efficacy of including performance incentives and rewards in the school funding formula. Lavy (2002) showed that performance incentives improved the achievements of low-performing students in Israeli high schools, more so than incentives provided for students with higher academic starting points. A study by Carnoy and McEwan (2000), based on data from Chile, is supportive of these findings; they also show that incentives are less beneficial for middle and upper class students. Angrist et al. (2007) extended Lavy's methodology to college students in Toronto, Canada, and found that incentives provided to schools with low-achieving students (i.e. with low starting points) improved performance levels.

\subsection{The Educational Improvement Curve}

An improvement that merits additional budgets in a school's educational achievement distribution (IEAD) is defined differentially, according to the school's starting point, i.e. its current educational achievement distribution (EAD). Based on Israeli high school examination data from the Trends in International Mathematics and Science Study (TIMMS), Mevarech and Liberman (2004) have argued that a school's level of achievement and its achievement gap are negatively correlated. If this were so for all schools, then allocating resources in a way that boosts student achievement would lead also to a narrowing of the achievement gap. But this is not the case for all schools; a negative relationship does not hold for low-achieving students (BenDavid-Hadar, 2008). Therefore, allocating resources to these schools in a way that raises student achievement would widen the achievement gap. 


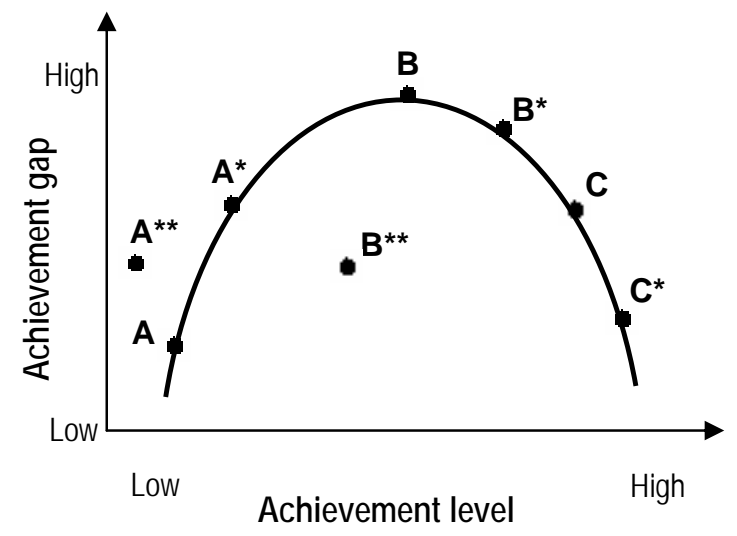

Figure 2: Education Improvement Curve: achievement level versus achievement gap

Consider three examples of schools, which we refer to as school types A, B and C, as shown in Figure 2. School A has an educational achievement distribution that is characterized by a low level of academic achievement and a narrow achievement gap, and is located at the left polar of the IEAD curve (Figure 2). School C has a desirable educational achievement distribution, combining a high level of achievement and a narrow achievement gap, and is located at the left polar of the curve. School B displays an achievement distribution characterized by average levels of achievement and a wide achievement gap, and is located at the extreme point between these two polar. The three points A, B and C lie on the Education Improvement Curve, which traces out a desired improvement path for schools progressing over time ${ }^{12}$. Incentives should be offered to encourage movement from left to right along the curve. $\mathrm{C}$ is the preferred school type, in which achievements are high and the education attainment gap is low.

An improvement in terms of the IEAD component, for which schools are rewarded with additional budgets, is defined differently for the above three school types. For school 
type A on the left side of the curve (a low-achieving school), a movement from point A to A* is defined as an IEAD. That is, even though the raising of the achievement level of school type A has resulted in an enlarged achievement gap, the move to $\mathrm{A}^{*}$ is regarded as an improvement, because the school is moving in the direction of school type C. However, a move from point A to point $\mathrm{A}^{* *}$ (where the achievement level has decreased and the achievement gap widened) would not be rewarded with additional funding, because there has not been an improvement in its achievement distribution. The mathematical formulation of IEAD is presented in the Appendix.

For school types B and C, at the center and the right side of the curve, IEAD is defined as movements from point $\mathrm{B}$ to $\mathrm{B}^{*}$ or from point $\mathrm{C}$ to $\mathrm{C}^{*}$, respectively. That is, if either of the school types B or C has managed to elevate its level of achievement and to narrow its overall achievement gap, it should receive a larger budget. However, a move from point $\mathrm{B}$ to point $\mathrm{B}^{* *}$, where the achievement gap is narrower while the level of achievement is lower, would not be rewarded with additional resources.

A crucial issue is the practicality of this approach in locating point $\mathrm{B}$, the turning point on the curve, in order to identify low-achieving schools for which IEAD is defined (an increase in the achievement level combined with a widening of the achievement gap). Using domestic and international data, such as Israeli matriculation examination data crosssectioned by different groups within Israel and the Program for International Students Achievement (PISA, 2006) data for different countries, it has been shown that this point occurs at the middle range of the variable discussed (BenDavid-Hadar, 2008). ${ }^{13}$

\section{Towards a new, unified formula}

\subsection{Moving from regression coefficients to formula weights}


As noted, there are four budgetary allocation methods in place at present in Israel: evenly-based allocation for high schools, separate needs-based formulas at middle schools for the two ethnic groups (relating to Hebrew and Arab education), and a needs-based formula at the primary school level. A basic decision was made in this study to develop a single, unified formula relating to all three levels of schooling and to both ethnic groups. While a regime of separate formulas (by school level, minority or special interest group) has the advantage of targeting the various formulas to the particular needs of the group concerned, it carries serious risks. Once the door for multiple formulas is opened, minority and special interest groups may exert pressure to receive their own tailored formulas, with elements and weights designed to advance their own narrow interests. The decision to develop a single, unified formula is in line with the recommendation of the Dovrat commission to extend the primary school formula to the other schooling levels, with minor changes.

We now proceed, in three stages, to derive the unified formula weights from the regression beta coefficients. The first stage is to average the variables' contributions to predicting educational performance (beta coefficients reported in Table 3), to obtain “preliminary” formula weights; these are reported in Column 1, Table 4. This procedure is justified since the same regression model was used for the two regressions and the resulting beta coefficients are very similar in the two cases. The second stage is to derive "adjusted" formula weights, taking into account policy considerations and additional information on the relative importance of these student background factors (Column 2, Table 4). In the third stage, adjusted weights are normalized to obtain relative weights for the formula. Thus, weight (w) for formula element i was computed as follows:

$$
w_{i}=\frac{\bar{b}_{i}}{\sum_{i=1}^{n} \bar{b}_{i}} W
$$


where $\bar{b}_{i}$ is the adjusted contribution for variable $\mathrm{i}$,
$\mathrm{n}$ is the number of variables, and
$\mathrm{W}$ is the total of needs-based weights in the formula.

\subsection{The new formula}

The new budget allocation formula, based on the above-mentioned regression analyses, is presented in Table 4. In Column 2, the adjusted contributions for each student background variable are shown; the sum of these estimated weights is 0.51 . Column 3 presents these needs-based weights, using equation (1), but normalized to 80; the IEAD element is accorded a weight of 20 - see below. The rest of this section provides an explanation of how the new formula elements were defined, with respect to the regression results.

Table 4: Proposed funding formula elements and weights

\begin{tabular}{|c|c|c|c|}
\hline Formula elements & $\begin{array}{c}\text { (1) } \\
\text { Beta } \\
\text { coefficients }\end{array}$ & $\begin{array}{l}\text { (2) } \\
\text { Adjusted } \\
\text { formula } \\
\text { weights }\end{array}$ & $\begin{array}{c}\text { (3) } \\
\text { Normalized } \\
\text { formula } \\
\text { weights }\end{array}$ \\
\hline \multicolumn{4}{|l|}{ Needs- based } \\
\hline $\begin{array}{l}\text { Parental education: } \\
\text { Mother's education level } \\
\text { Father's education level }\end{array}$ & $\begin{array}{l}0.23 \\
0.06\end{array}$ & $\begin{array}{c}23 \\
(15) \\
(8)\end{array}$ & $\begin{array}{l}23 \\
13\end{array}$ \\
\hline Number of siblings & 0.04 & 4 & 6 \\
\hline New immigrant status & 0.05 & 5 & 8 \\
\hline $\begin{array}{l}\text { New immigrants from } \\
\text { developing countries status }\end{array}$ & -- & 5 & 8 \\
\hline Residence: SES & 0.02 & 2 & 3 \\
\hline
\end{tabular}




\begin{tabular}{|l|c|c|c|} 
Ethnicity & 0.06 & 12 & 19 \\
\hline Total & 0.46 & 51 & 80 \\
\hline Improvement & -- & -- & 20 \\
\hline IEAD & -- & -- & 100 \\
\hline Total & & & \\
\hline
\end{tabular}

From the regression analysis reported above, it is evident that parental education, especially mother's education, is the most important variable in explaining the variance in student achievement. Based on these results, as well as on other regressions executed without interaction effects and separate regressions by ethnic group, we conclude that the parental education interaction is an important variable in explaining student performance; its overall estimated contribution effect is 23 (Table 4, Column 2). This is normalized to give a formula weight of 36 (Column 3). However, mother's education has a larger effect in explaining student performance than father's education; its effect is about twice that of the father's education. ${ }^{14}$ Thus, the combined parental education weight is split, to give a formula weight of 23 for mother's education and 13 for father's education.

Based on the measured beta coefficient $\left(0.04^{* *}\right.$, Table 3$)$, the measured contribution for number of siblings is 0.04 (Table 4, Column 1); its adjusted weight is 4 (Column 2) and the normalized weight is 6 (Column 3).

The measured beta coefficients for new immigrants are $0.07^{* *}$ and $0.03^{* *}$, as shown in Table 3, from which an averaged contribution of 0.05 is derived (Table 4, Column 1), giving an adjusted formula weight of 5 and a normalized weight of 8 . The measured beta coefficient of the residence SES is $0.04 * *$ (for the performance level variable) and not significant, close to zero (for the quality of performance variable), as shown in Table 3. These 
results lead to an averaged contribution of 0.02 (Table 4, Column 1), an adjusted formula weight of 2 and a normalized weight of 3.

Ethnicity plays an important role in explaining achievement gaps in Israel (BenDavidHadar, 2008) and is included prominently in the new formula. We adjust the beta coefficient of 0.06 (Table 4, Column 1) upwards, to retain adequate compensation for students from ethnic minorities. The beta coefficient for ethnic group does not reflect adequately the role of this variable in accounting for student performance, given the wide range in the estimated contribution effects (i.e. a stronger effect at the primary school and middle school levels and a much weaker effect at the high school level). The relatively low beta coefficients at the high school level $\left(0.04^{* *}, 0.07^{* *}\right)$ compare with much higher beta coefficients from aggregated school level regressions on the middle school and primary school levels $\left(0.36^{* *}\right.$ and $0.45^{* *}$, respectively $)^{15}$. Since it is our intention to create a uniform formula for all schooling levels, we saw it fit not to directly "translate" the beta coefficient derived from the high-school level regressions, but rather to take into account the impact of ethnicity at the other schooling levels, assigning to ethnicity a higher adjusted weight of 12, normalized to 19.

Finally, the weight for new immigrant from developing countries status variable was adjusted. Following the practice in the current formula for primary schools, an additional weight is accorded to the new immigrant category, for new immigrants from developing countries. This compensates schools in which many new immigrant students from developing countries are enrolled, with low educational performance starting points. The performance of students of Ethiopian origin, the most recently arrived new immigrant group, are lower than that of other students $\left(\mathrm{t}=2.53^{* *}, \mathrm{df}=394\right.$, in Hebrew middle schools). Similar results are found for students whose parents were born in Ethiopia $\left(\mathrm{t}=2.3^{* *}, \mathrm{df}=394\right.$, based on the authors' calculations, available on request). An additional element, with a weight of 5 (Table 
4, Column 2) is given for new immigrants from developing countries, normalized to a weight of 8 .

In addition to these needs-based weights, the new budget formula should include the incentive element, the IEAD, which is missing in the current formula. According to this element, a school's budget will be enlarged if the school manages to achieve IEAD. Including an IEAD element in the proposed formula supports a central objective of the schooling process, which is to achieve progress by improving students' starting points. A weight of 20 is assigned to the IEAD element (Table 4, Column 3). This is based on the results of school improvement, researched by Hayes and Taylor (1996) using Dallas school data. It was found that the schools' value-added beta coefficient explains 10 percent of the total explained variance in performance. However, the IEAD was assigned a larger weight of 20, representing a reward for -and an incentive to- academic improvement. In future work, the IEAD weight will be measured directly, by using value-added models on longitudinal Israeli data that are not currently unavailable, but will be forthcoming in the near future. The direct measure of schools' value-added and its weight in explaining variance in achievement may indicate the need to assign an even larger weight to IEAD.

\subsection{Comparing proposed and current formulas}

Table I facilitates a comparison of the proposed need-based elements and weights with those currently in use in the primary and middle school formulas; our proposed new formula weights are listed in Column $3 .{ }^{16}$ First, we may compare parental education: the weights accorded to parents' education in the current differential indexes for primary and secondary schools are inappropriate. For primary schools, both parents are accorded the same weight (15); but our regression analyses have shown that mother's education is the more important variable in explaining student achievement variance. Thus the current weight assigned to mother's education is too low and that of father's education is too high. Mother's 
education is not even included in the middle school formula, in which the weight assigned to father's education is 25, far larger than its true effect on achievement.

The weights assigned to the number of siblings in the needs-based elements of the current formulas are clearly too high. The current weights assigned to number of siblings at the primary school and middle school levels range between 10 and 15, while the beta coefficient for this variable in our regression analysis merits a weight of no more than 5.

The current formulas are inefficient in assigning total new immigrant status a weight as high as 30 for primary schools and only 15 for middle schools, even though middle schools suffer from a wider achievement gap than do primary schools (Lavy, 2003).

The proposed element weight for compensating schools with students from low SES residence locations (and low achievement starting points) is lower than in the current primary and middle school formulas. The periphery element in the current formula, a proxy for SES level, is defined in terms of geographical distance from large cities. But this definition is not very appropriate as an SES measure, because some of the most remote residences enjoy a high SES, whereas some large cities (such as Jerusalem) suffer from a low SES. Our measure of SES level is more accurate, accounting for the weight differences in the current and proposed formulas.

The national priority status element in the current primary school budgeting formula is deemed inappropriate in a needs-based formula and, indeed, is currently being dropped (see discussion in Section 6). Moreover, this component was not found to be a significant factor in explaining the achievement gap (BenDavid-Hadar, 2008). An additional instance of the inefficiency of the current formulas is the absence of an ethnicity element. The parental income element in the middle school formula is problematic because parental income and parental education are highly correlated. 


\section{Recent initiatives}

In the last few years, school funding reform has come to the fore in public debate. While, on the whole, the initial steps in this process were largely positive, more recent initiatives have been highly regressive and may lead to an increase in horizontal and vertical inequities and a widening of the achievement gap.

The Dovrat Commission (2005), appointed to examine the state of schooling in Israel and all its ramifications, recommended the extension of the primary schools' needs-based formula (Shoshani’s differential index) to middle schools and high schools. This entailed applying to the two higher levels of schooling the equitable principal used in primary school budget allocation (where the school budget is the product of the number of students times the differential index of each student). This recommendation was accompanied by several proposed changes in the formula elements (the omission of the national priority status element and the insertion of an income per capita element), by a small change in the element weights (mother's education enlarged to $20 \%$, father's education reduced to $10 \%$ ), and the allocation of the school budget in monetary terms rather than in hours. Due to vested interest opposition, the overall recommendations of the commission, including those relating to school funding, were not implemented. Subsequently, an Israeli Supreme Court decision in 2006 stated that the national priority status element discriminated against minority students. This ruling led to the removal of this element from the primary school funding formula.

With the national priority status element jettisoned from the primary school allocation formula, some adjustment to the Shoshani Index was necessary. In practice, it was replaced in 2007 by a virtually new formula, the "Strauss Index", which encompassed changes in both the formula elements and their weights. It comprises four elements, as follows: 
parental education, 40\%; parental income, 20\%; periphery, 20\%; continent of birth of the student or parents, 20\%. All four elements are problematic.

The increase in the weights assigned to parental education (from 30 to 40 points) and to the periphery element (10 to 20 points) is not based on empirical evidence. Moreover, the parental education element was unified; this goes against the Dovrat recommendations and our own empirical findings, which indicate that the mother's education level should be accorded a separate, larger formula weight.

It has been noted that the current definition of periphery does not reflect SES differences very accurately. Moreover, while the inclusion of the parental income element will result in larger budget allocations to minority student schools, it constitutes a form of double counting as parental education and income are highly correlated. Finally, the continent of birth element discriminates against endogenous ethnic minority groups.

These new formula weights were assigned on an ad hoc basis; this represents a major departure from the approach advocated in this paper, that the allocation formula should be based on research that mainly focuses on the measured relationships between student performance and various explanatory variables and not on arbitrary decisions.

Even more damaging, however, is the decision to accompany the Strauss Index with a comprehensive reform of the primary school allocation mechanism overall, starting in 2008. This mechanism works as follows: 95 percent of the total budget is to be allocated to primary schools, on an even basis, regardless of their academic attainment starting point and needs (compared with the present allocation of 87 percent). The remaining budget (five percent) will be allocated according to the Strauss needs-based formula. This reform represents a highly retrograde step and a departure from the equitable principle of the Shoshani Index, also advocated by the Dovrat Commission, according to which a sizeable part of the school budget is the product of the number of students by the average differential (student) index for the 
school. This overall change essentially marginalizes any equitable effects of the Strauss Index, as five percent of the total allocation is unlikely to make a sizable indent on the large achievement gap (compared with the present thirteen percent). Moreover, according to this two-stage allocation, low-achieving schools will receive even lower budgetary allocations than at present and an enlargement of the achievement gap is expected to follow.

Thus school funding in Israel has now taken a new direction, emphasizing "adequate” (equal) funding for schools based on student numbers rather than needs-based funding. This, plus the absence of an improvement component in the funding formula, is likely to lead to greater vertical and horizontal disparities and to an unfortunate widening of the achievement gap, an outcome that is the very opposite of declared policy objectives and societal needs. 


\section{References}

Adnett, N., Bougheas, S., \& Davies, P. (2002). Market-based reform of public schooling: some unpleasant dynamics. Economics of Education Review, 21 (4), 323330.

Angrist, J., Lang, D., \& Oreopoulos, P. (2007) Incentives and services for college achievement: evidence from a randomized trial. Paper presented at a conference of education and human capital in Israel on December 16, 2007, Jerusalem, organized by the Central Bank of Israel Research Department.

Ben-David, D. (2000). Teach your children well: planning the seeds of education and harvesting the benefits of trade. Retrieved on June 9, 2007 from http://spirit.tau.ac.il/public/bendavid/index_research.html.

BenDavid-Hadar, I. (2008). Inequality in education: investigating the achievement gap in Israel. Education and Society 26 (3).

Canton, E. \& Webbink, D. (2002). The Dutch education system: Options for institutional reform. CPB Report, 2002/2: The Hague, 26-31. Retrieved on June 9, 2007 from http://www.cpb.nl/eng/pub/cpbreeksen/cpbreport/2002 2/

Central Bank of Israel. (2008). The Social Services Report of 2008. Jerusalem, Israel: Bank of Israel. (In Hebrew). Chapter 8.

Central Bureau of Statistics. (2006). Characterization and classification of local authorities by the socio-economic level of the population. Jerusalem, Israel: CBS. Retrieved on January 3, 2009 from http://www.cbs.gov.il/

Cohn , E. \& Geske, T.G. (1990). The Economics of Education. Oxford: Pergamon Press.

Dovrat Commission. (2005). Report of the National Task Force for the Advancement of Education. Jerusalem, Israel: Ministry of Education. (in Hebrew).

Hayes, K. J. \& Taylor, L.L. (1996). Neighborhood school characteristics: What signals quality to homebuyers? Federal Reserve Bank of Dallas Economic Review, fourth quarter, 2-9.

Hanushek, A. E “Outcomes, Costs, and Incentives in Schools”. Chapter 3. pp. 2952. in Hanushek, A. E., and Jorgenson, W. D. Eds. (1996). Improving America's Schools: The Role of Incentives. Board on Science, Technology, and Economic Policy, National Research Council

Klinov, R. (2008). The Differential Index in Israel: A Report for the Chief Scientist of the Ministry of Education. Jerusalem, Israel: Ministry of Education. (In Hebrew). Retrieved on December 23, 2008 from http://economics.huji.ac.il/facultye/klinov/Gender_Preference.pdf 
Kopp, Y. (2008). The Social Services of Israel. Jerusalem, Israel: Taub Centre. (In Hebrew).

Lavy, V. (2002). Evaluating the effect on matriculation achievement of teachers or schools' incentives. Discussion paper number A01.06. (in Hebrew). The Falk Institution for Economic Research in Israel. Retrieved on June 9, 2007 from http://pluto.huji.ac.il/ msfalkin/digest.htm

Lavy, V. (2003). Education in last decades and its effect on social gaps. In Shye, S., and Zion, N. (Eds.), Education and social justice in Israel: On equality in educational opportunities pp. 44-64. The Van- Leer Institution, Jerusalem, Israel, (in Hebrew).

Levacic, R., \& Vignoles, A. (2002). Researching the links between school resources and student outcomes in the UK: A Review of issues and evidence. Education Economics, 10(3), 313-331.

McEwan, P.J. \& Carnoy, M. (2000). The effectiveness and efficiency of private schools in Chile's Voucher System. Educational Evaluation and Policy Analysis, 22(3), 213- 39.

Mevarech, Z. \& Liberman, G. (2004). Equality and excellence: Does excellence encourage inequality? Megamot, 43, 195- 216 (in Hebrew).

Muralidharan, K., \& Sundararaman, V. (2008). Teacher Incentives in Developing Countries: Experimental Evidence from India. Working Paper. Nashville: National Center on Performance Incentives.

National Insurance Institute of Israel. (2006). Israel poverty report. (in Hebrew). Jerusalem, Israel: NII. Retrieved on January 3, 2009 from http://wwwz.btl.gov.il

Nesher, P. (1996). Nurturing Index. Jerusalem, Israel: Ministry of Education. (in Hebrew).

Odden, A. \& Picus, L.O. (2000). School finance: A policy perspective. Second addition McGraw- Hill.

Owens, T. \& Maiden, J. (1999). A comparison of interschool and interdistrict funding equity in Florida. Journal of Education Finance 24 Spring, 305-318.

Ritzen, J., Van Dommelen, J., \& De Vijlder, F. (1997). School finance and school choice in the Netherlands. Economics of Education Review, 16 (3), 329- 335.

Ross, K., \& Levacic, R. (1999) (Eds.). Needs-Based Resource Allocation in Education: Via Formula Funding of Schools. Paris: UNESCO Publishing.

Shoshani Committee. (2001). Report of the Committee appointed for Examining the Budgetary Allocation Mechanism's. Jerusalem, Israel: Ministry of Education. (in Hebrew). Retrieved on June 9, 2007 from 
http://cms.education.gov.il/NR/rdonlyres/3F2D67A5-0E18-4078-A0F7-

D39A81F9FB8F/5660/doch_male1.doc

Springer, G.M. \& Winters, A. M. (2009). New York City's School-Wide Bonus Pay Program: Early Evidence from a Randomized Trial. Working paper 2009-02. National Center on Performance Incentives: Vanderbilt University

Woessmann, L., (2006). Efficiency and Equity of European Education and Training Policies. CESifo Working Paper No. 1779.

Shambaugh, L.S., Chambers, J.G., \& DeLancey, D. (2008). Implementation of the weighted student formula policy in San Francisco: a descriptive study of an equitydriven, student-based planning and budgeting policy (Issues \& Answers Report, REL 2008-No. 061). Washington, DC: U.S. Department of Education, Institute of Education Sciences, National Center for Education Evaluation and Regional Assistance, Regional Educational Laboratory West. Retrieved from http://ies.ed.gov/ncee/edlabs. 


\section{Appendix}

The mathematical formulation of IEAD for school type A is as follows:

$\operatorname{IEAD}(\mathrm{A})=$

$\begin{cases}\mathrm{F}(\Delta \mathrm{y}, \Delta \mathrm{s}) \text { if } \frac{y_{j}^{t}-y_{j}^{t-1}}{Y_{j}^{t-1}}>0, \frac{s_{j}^{t}}{s_{j}^{t-1}}>1 \\ 0 \quad \text { otherwise }\end{cases}$

$y_{j}^{t}, y_{j}^{t-1}$ are the $\mathrm{j}$ - th school level of achievement at time t and $\mathrm{t}-1$ and

$s_{j}^{t}, S_{j 1}^{t-1}$ are the j- th school achievement gap at time t and t-1.

The mathematical formulation of IEAD for school type B or C is as follows:

$\operatorname{IEAD}(\mathrm{B}, \mathrm{C})=$

$\left\{\begin{array}{l}\mathrm{F}(\Delta \mathrm{y}, \Delta \mathrm{s}) \text { if } \frac{y_{j}^{t}-y_{j}^{t-1}}{y^{t-1}{ }_{j}}>0, \frac{s_{j}^{t}}{s_{j}^{t-1}}<1 \\ 0 \quad \text { otherwise }\end{array}\right.$ 


\section{Endnotes}

$1 \quad$ These cases resemble Israel's societal diversity and also include sizeable ethnic minorities.

$2 \quad$ Hawaii constitutes another example of a full state funding program that satisfies the principle of horizontal equity, since each district is not permitted to spend less than the level set by state, nor to exceed it (Odden and Picus, 2000).

3 Data from Israel Central Bureau of Statistics, November 2009 http://www.cbs.gov.il/

$4 \quad$ Data from the 2006 Israeli Poverty Report. http://www.btl.gov.il

$5 \quad$ For more details, see the website http://cms.education.gov.il/NR/rdonlyres/0D4A1917-8256-42D4A55A-AFAD4D2A3A3B/6934/Section_A.pdf

Official education: official educational institutions are owned by the state and/or by the local authorities and are listed in the Official Gazette as official schools.

$7 \quad$ The total budget for primary schools providing Hebrew education is allocated as follows: $60 \%$ for state-general schools, $20 \%$ for state-religious schools and $20 \%$ for other religious schools. The secondary education budget is allocated as follows: $70 \%$ state-general schools, $20 \%$ for state-religious school, and $10 \%$ for other religious schools.

$8 \quad$ Mixed cities are those in which Jewish and non-Jewish populations live together.

$9 \quad$ Matriculation examinations are the final tests prior to receiving a high-school diploma (Bagrut diploma) in Israel. To be eligible for a diploma, a student must gain a minimum of 21 units in different subjects and a pass grade (55 percent or more) in the obligatory subjects (such as Mathematics and English).

$10 \quad$ Ethnicity was also analyzed in various regression runs, in terms of separate sub-categories for various minority groups (Arab students, Druze students, and Bedouin students); in this paper we report only the results relating to the overall ethnic group dummy variable.

11 The value of the variable mother's education for minority students is very low, almost zero.

12 In the short run, since achievement have an upper limit, the shift along the curve from left to right represents improvement, while on the long run, since knowledge is not limited, the shift of the curve represents a breakthrough in the current frontiers of knowledge.

$13 \quad$ From a theoretical point of view, point B can also be considered to occur after the fourth decile of the student achievement distribution. This conclusion is based on Israeli data, where the first lower four deciles include minority and low SES groups and students who reside in the periphery - these groups account for 40 percent of the population. Thus the turning point is between the fourth and fifth decile. Other countries will display different turning points, according to societal diversity, relating to the proportion of minorities, low SES groups and rural students in the total population.

14 The regression with the interaction effect shows the mother's education to have an effect, additional to the interaction effect, of $0.06^{* *}$ at the high school level (Table 3).

15 Jewish students perform better than minority students, both at the middle-school level $\left(\mathrm{t}=3.13^{* *}\right.$, $\mathrm{df}$ =366) and at the primary school level (using Scheffe tests for group mean differences in Mathematics, Science, and English, F $\left.(3,2122)=98.7^{* *}\right)$.

$16 \quad$ Strictly speaking, our proposed needs-based formula weights should be raised by 25 percent (normalized to a 100), for comparison with the weights in the current formulas. 